\title{
MYCL1 Amplification and Expression of L-Myc and c-Myc in Surgically Resected Small-Cell Lung Carcinoma
}

\author{
Jing Qin ${ }^{1,2}$, Fajun Xie ${ }^{1,2}$, Chenghui $\mathrm{Li}^{1}{ }^{1}, \mathrm{Na} \mathrm{Han}^{1}$ and Hongyang $\mathrm{Lu}{ }^{1,2 *}$ \\ ${ }^{1}$ Department of Thoracic Medical Oncology, Cancer Hospital of the University of Chinese Academy of Sciences (Zhejiang Cancer \\ Hospital), Institute of Basic Medicine and Cancer (IBMC), Chinese Academy of Sciences, Hangzhou, China, ${ }^{2} Z$ hejiang Key \\ Laboratory of Diagnosis and Treatment Technology on Thoracic Oncology (Lung and Esophagus), Zhejiang Cancer Hospital, \\ Hangzhou, China
}

OPEN ACCESS

Edited by: Anna Sebestyén,

Semmelweis University, Hungary

*Correspondence: Hongyang Lu luhy@zjcc.org.cn

Received: 10 February 2021 Accepted: 04 June 2021 Published: 18 June 2021

Citation:

Qin J, Xie F, Li C, Han N and Lu H (2021) MYCL1 Amplification and Expression of L-Myc and C-Myc in Surgically Resected Small-Cell Lung Carcinoma. Pathol. Oncol. Res. 27:1609775. doi: 10.3389/pore.2021.1609775
Purpose: The Myc family, especially C-MYC and MYCL1, has been found involved in small-cell lung carcinoma (SCLC). Identification of the frequency of C-MYC and MYCL1 expression among SCLC patients may help to identify potential targets for therapeutic intervention. Our aim was to detect MYCL1 amplification, L-Myc and c-Myc expression, and investigate clinicopathological characteristics and survival status in patients with surgically resected SCLC.

Methods: MYCL1 amplification was detected using fluorescence in situ hybridization (FISH), while L-Myc and c-Myc protein expressions were determined using immunohistochemistry $(\mathrm{IHC})$ in the primary tumors of 46 resected SCLC patients.

Results: Among the 46 evaluated specimens, MYCL 1 amplification was identified in 3/46 cases (6.5\%). One of the positive cases was MYCL1 gene amplification combined with fusion. $3 / 46$ (6.5\%) was positive for L-myc protein expression, and 4/46 (8.7\%) was positive for c-Myc protein expression.

Conclusion: Our study firstly multidimensional explored the expression of MYCL1 amplification, L-Myc and C-Myc protein and investigated clinicopathological characteristics and survival status in patients with surgically resected SCLC, which makes a contribution to subsequent research and therapeutic strategies.

Keywords: immunohistochemistry, small-cell lung carcinoma, C-MYC, fluorescence in situ hybridization, MYCL1 amplification, L-myc

\section{INTRODUCTION}

Lung cancer is a leading cause of cancer-related death globally and domestically [1,2]. Small-cell lung carcinoma (SCLC), accounting for about $15 \%$ of all lung cancers, is considered as an aggressive neuroendocrine lung cancer and has a high propensity for early development and extensive metastatic dissemination. SCLC is a lethal disease characterized by rapid recurrence and dismal prognosis, and there is no other effective treatment option except chemotherapy and radiation. The median overall survival (OS) for patients with limited-disease and extensive-disease SCLC is 15-20 months and 8-10 months, respectively [3]. Apart from the recent advances in immunotherapy, the medical management of SCLC has changed little over several decades [4]. Hence, it is crucial to explore novel molecular targets activated by genetic alterations in SCLC. 
Recently, the whole-genome profiling has been used to obtain information about the alterations of the activated genes in SCLC. The amplification of Myc family oncogenes MYCL1 (1p34), MYCN (2p24), and C-MYC (8q24) was detected frequently for mutually exclusive interactions [5]. Currently, Ireland et al. have showed that C-MYC drived SCLC subtype evolution via reprogramming neuroendocrine peculiarity, which revealed a conserved trajectory from neuroendocrine to nonneuroendocrine subtypes, and a molecular evolution from $\mathrm{ASCL}^{+}$to $\mathrm{NEUROD}^{+}$to $\mathrm{YAP}^{+}$subtypes [6]. Hwang et al. have explored $C-M Y C$ amplification by chromogenic in situ hybridization (CISH), and it was identified in $9 \%$ of SCLCs and was correlated with protein expression. Regrettably, 83\% cases were biopsies and only $17 \%$ cases were larger specimens [7]. In addition, the role of MYCL1 remains unclear in SCLC. MYCL1 exerts weaker effects than c-Myc in cell growth, apoptosis and transformation [8]. However, it makes the reprogramming of fibroblasts into the induced pluripotent stem cells [9] and L-Myc expression by dendritic cells is required for optimal T-cell priming [10]. MYCL1 is amplified and overexpressed in some malignancies [11]. L-Myc acts as a transcription factor and is targeted by the transcription factor achaete-scute homolog-1 (ASCL1), which plays crucial roles in promoting the progression of SCLC [12]. Xiong, F et al. have found that single-nucleotide polymorphism (SNP) of an intron of MYCL1 was associated with the susceptibility to SCLC [13]. The amplification and expression of MYCL1 were observed in a majority of human SCLC cell lines [14]. However, correlations of MYCL1 and C-MYC with clinicopathological characteristics and outcomes in SCLC remain largely unknown.

Hence, the goal of this study was to detect MYCL1 amplification, L-Myc and c-Myc expression, and investigate clinicopathological characteristics and survival status in patients with surgically resected SCLC in China.

\section{MATERIALS AND METHODS}

\section{Study Population}

We retrospectively collected 59 consecutive patients with resected SCLC at Cancer Hospital of the University of Chinese Academy of Sciences (Zhejiang Cancer Hospital) in China (Hangzhou) between April 2008 and November 2016. The pathological diagnosis of SCLC was based on the standard criteria defined by the World Health Organization (WHO) [15]. The tumor stage was classified according to the tumor-node-metastasis (TNM) classification for lung cancer, eighth edition [16]. Eight patients who experienced neoadjuvant chemotherapy or chemoradiotherapy were excluded from our study due to disturbed effects of treatment-induced DNA damage. Five cases were removed because of insufficient tissue remaining. Therefore, a total of 46 patients with SCLC who underwent surgery were enrolled in the present study. Formalin-fixed paraffin-embedded (FFPE) blocks from 46 SCLC patients were retrospectively collected. Tumor tissues were taken from surgically resected tumors. The clinical characteristics (gender, age, smoking status, tumor stage, lymph node metastasis and
TABLE 1 | Clinical characteristics of 46 SCLC patients.

\begin{tabular}{|c|c|}
\hline Characteristics & Cases (n) \\
\hline \multicolumn{2}{|l|}{ Sex } \\
\hline Male & 36 \\
\hline Female & 10 \\
\hline \multicolumn{2}{|l|}{ Age } \\
\hline$<60$ & 24 \\
\hline$\geq 60$ & 22 \\
\hline \multicolumn{2}{|l|}{ Smoking } \\
\hline Non-smoker & 13 \\
\hline Light smoker ( $\leq 10$ pack-years) & 3 \\
\hline Moderate smoker (10-20 pack-years) & 6 \\
\hline Heavy smoker smokers ( $\geq 20$ pack-years) & 24 \\
\hline \multicolumn{2}{|l|}{ Stage } \\
\hline $\mathrm{IA}$ & 17 \\
\hline $\mathrm{IB}$ & 5 \\
\hline$\| A$ & 0 \\
\hline$\| \mathrm{B}$ & 9 \\
\hline IIIA & 14 \\
\hline IIIB & 1 \\
\hline \multicolumn{2}{|l|}{ Lymph node metastasis } \\
\hline NO & 22 \\
\hline $\mathrm{N}+$ & 24 \\
\hline \multicolumn{2}{|l|}{ Brain metastasis } \\
\hline NO & 34 \\
\hline YES & 12 \\
\hline
\end{tabular}

brain metastasis) were obtained from the medical records (Table 1). This study was approved by the medical Ethics Committee of Zhejiang Cancer Hospital.

\section{Immunohistochemistry}

IHC was performed on FFPE tumor tissues using anti-L-Myc antibody (ab28739, Abcam Inc. Cambridge, MA, United States) and anti-c-Myc antibody (ab32072, Abcam) as per the manufacturer's instructions. The anti-L-Myc antibody (ab28739) consists of rabbit polyclonal to L-Myc. The anti-cMyc antibody (ab32072) is a rabbit monoclonal antibody and is specific for the endogenous c-Myc.

Tumor specimens were fixed with $10 \%$ formalin and embedded in paraffin, followed by deparaffinization, rehydration, endogenous peroxidase blocking, and antigen retrieval. Then the specimens were blocked with $1 \%$ bovine serum albumin (BSA) for $10 \mathrm{~min}$ at room temperature and incubated with anti-L-Myc antibody (ab28739, 1:200, Abcam) or anti-c-Myc antibody (ab32072, 1:100, Abcam) overnight at $4^{\circ} \mathrm{C}$, followed by incubation with iVisionTM Poly-HRP Sheep anti-rabbit secondary antibody (DD13030, Ascend Bio. purchased by Xiamen Talent Biomedical Technology Co., Ltd. People's Republic of China) for $1 \mathrm{~h}$ at $37^{\circ} \mathrm{C}$. Next, $3,3^{\prime}$ diaminobenzidine (DAB) kit (KS-003030, Ascend Bio.) was used to visualize the immunoreactivity. PBS was used as negative control instead of primary antibody. Each slide was evaluated independently by two pathologists who were blinded to clinical information. Interpretation of L-Myc expression level: if $\geq$ $10 \%$ cells showing brown color were defined as "positive expression"; No staining or positive staining in less than $10 \%$ cells was defined as "negative expression". Interpretation of c-Myc expression level: if $\geq 40 \%$ cells showing brown color 
were defined as "positive expression"; No staining or positive staining in less than $40 \%$ cells was defined as "negative expression". When different interpretations occurred, slides were reviewed until consensus was obtained. Results interpretation referred to the published paper [11,17].

\section{Fluorescence in situ Hybridization}

FISH was performed on FFPE tumor tissues using MYCL1 Break Apart Probe (Empire Genomics LLC, purchased by Genediagnostic. Inc. People's Republic of China) according to the manufacturer's instructions.

The MYCL1 Break Apart Probe consists of DNA labeled with Spectrum Green and Spectrum Orange. The DNA probe hybridizes to chromosome $1 \mathrm{p} 34.2$ in normal metaphase spreads and interphase nuclei.

The FFPE sections $(4-5 \mu \mathrm{m})$ were deparaffinized, treated with Pretreatment Solution Citric at $98^{\circ} \mathrm{C}$, and digested in pepsin solution. The probe $(10 \mu \mathrm{l})$ was added to each slide. The target DNA and probes were co-denatured at $83^{\circ} \mathrm{C}$ for $5 \mathrm{~min}$ and incubated in a humidified hybridization chamber at $37^{\circ} \mathrm{C}$ overnight, followed by three post-hybridization washes in $1 \times$ wash buffer $\mathrm{A}$ at $37^{\circ} \mathrm{C}, 5 \mathrm{~min}$ each. Finally, the slides were air-dried and counterstained with 4',6diamidino-2-phenylindole (DAPI)/antifade solution. Signals for each locus-specific FISH probe were assessed under an Olympus BX51 microscope (Olympus Corp.). FISH results were evaluated by two pathologists with close correlation regarding the site of interest in FISH analysis with histomorphology in hematoxylin-eosin (HE) stained slides.

The MYCL1 FISH break-apart results were based on at least 100 evaluable tumor cell nuclei. A break-apart/split FISH signal was considered as abnormal in case of "orange and green split-signals" with a clear-cut distance of at least two signal diameters. A cut-off of at least 15\% [mean +3 standard deviation (SD)] "break-apart" events was used as the threshold for MYCL1 FISH-abnormal.

The MYCL1 FISH amplification results were based on at least 100 evaluable tumor cell nuclei. The number of orange-green fusion signals in each nucleus was counted and calculated. A cutoff of 2.25 (mean $+3 \mathrm{SD}$ ) signals on an average was used as the threshold for MYCL1 FISH-abnormal.

\section{Follow-Up}

The follow-up deadline was February 10, 2020. Among all the patients, 21 patients were alive, and 25 patients were dead. The survival time was calculated from the date of pathological diagnosis.

\section{Statistical Analyses}

Statistical analysis was performed using SPSS 15.0 statistical software (SPSS Inc. Chicago, IL, United States). All data were presented as mean $\pm \mathrm{SD}$.

\section{RESULTS}

\section{Prevalence of MYCL1 amplification and Fusion by FISH}

MYCL1 amplification and fusion were evaluated by FISH in 46 SCLC specimens. As shown in Figure 1, casel represented
MYCLlamplified patient. According to our results, three cases showed MYCL1 gene alterations, where two were amplification and the other was amplification combined with fusion. MYCL1 gene alterations were identified in 3 of 46 cases (6.5\%). Three amplified cases were positive for high MYCL1 gene copy number, 17, 5.45, and 5.7 per nucleus, respectively. It was demonstrated that these MYCL1 gene alterations were caused by the increased gene copy number gain on the chromosome. In addition, the ratio of isolated signal cells was $53.8 \%$ in the case with MYCL1 fusion. Of the three positive patients, their ages were more than 60 years old. Two male patients had moderate and heavy smoking history staged with IA and IIB respectively, and one female patient without smoking exposure staged with IIB. No brain metastasis was observed in the above three positive cases during the follow-up (Table 2). All three positive patients had died. The DFS time of these three cases was 12 months (m), $20 \mathrm{~m}, 41 \mathrm{~m}$, and their OS was $21 \mathrm{~m}, 26 \mathrm{~m}, 51 \mathrm{~m}$, respectively. Of the MYCL1 non-amplification patients, their median DFS were $42 \pm$ $5.82 \mathrm{~m}$, and their median OS were $48 \pm 5.22 \mathrm{~m}$, respectively. The survival curves of DFS and OS were shown in Figures 2A,B.

\section{Prevalence of L-Myc Protein Expression by IHC}

The L-Myc protein expression was evaluated in 46 SCLC cases. The L-Myc protein was located in the nucleus. As shown in Figure 1, case 2 represented positive patient of L-Myc protein expression. Of the evaluated specimens, $6.5 \%$ ( 3 of 46 ) of specimens were positive for L-Myc protein expression. Of the three positive patients, two patients were less than 60 years old and the other one more than 60 years old. They were all male and moderate and heavy smokers with stage I. No brain metastasis was observed in the above three positive cases during the follow-up (Table 2). Of the three positive patients, two patients were alive, and one patient had died. DFS and OS of the deceased patient were $55 \mathrm{~m}$ and $61 \mathrm{~m}$, respectively. Of the L-Myc protein expression negative patients, their median DFS and OS were $39 \pm 5.79 \mathrm{~m}, 46 \pm 5.22 \mathrm{~m}$, respectively. The survival curves of DFS and OS were shown in Figures 2C,D.

\section{Prevalence of c-Myc Protein Expression by IHC}

The c-Myc protein expression was evaluated in 46 SCLC cases. The c-Myc protein was located either in the nucleus or both in the cytoplasm as well as the nucleus (Figure 3). Among the evaluated specimens, $8.7 \%$ (4 of 46 ) were positive for c-Myc protein expression. Of the four positive patients, two patients were less than 60 years old and the other two more than 60 years old. They were all male and three of them moderate and heavy smokers and the other one was a light smoker. Three cases were stage at IIIA and one was stage at IA. No brain metastasis was observed in the above three positive cases during the follow-up (Table 2). Of the four positive patients, all patients were alive. Of the $\mathrm{c}-\mathrm{Myc}$ protein expression negative patients, their median DFS and OS were $35 \pm 4.90 \mathrm{~m}, 42 \pm 4.35 \mathrm{~m}$, respectively. The survival curves of DFS and OS were shown in Figures 2E,F. 


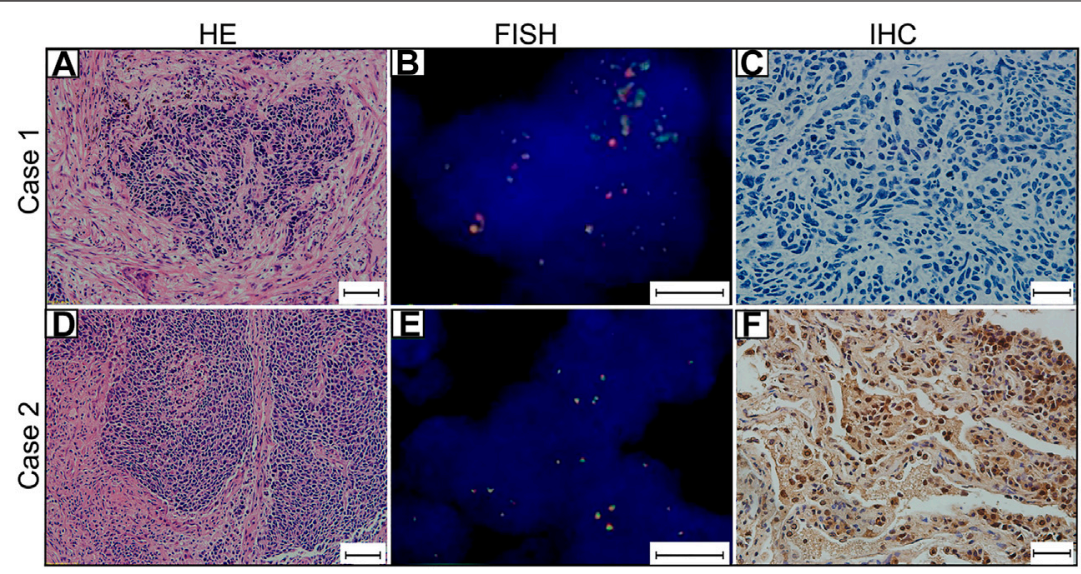

FIGURE 1 | MYCL1 Fluorescence in situ hybridization (FISH) and L-Myc Immunohistochemistry (IHC) in small-cell lung carcinoma (SCLC). Case 1 represents MYCL1 amplification patient. (A) The representative image of hematoxylin and eosin (HE) staining (scale bar $50 \mu \mathrm{m}$ ). (B) MYCL1 amplification by FISH (scale bar $10 \mu \mathrm{m}$ ). Green spectrum denotes DNA $3^{\prime}$-end and Orange spectrum denotes DNA 5'- end. (C) L-Myc protein expression negative (scale bar 20 $\mu m$ ). Case 2 represents L-Myc protein expression positive patient. (D) The representative image of HE-staining (scale bar $50 \mu m$ ). (E) MYCL1 non-amplification (scale bar $10 \mu \mathrm{m})$. (F) L-Myc protein expression positive (scale bar $20 \mu \mathrm{m}$ ). Brown color of the nucleus was defined as positive staining.

TABLE 2 | Clinicopathological data of MYCL1 and c-Myc status.

\begin{tabular}{|c|c|c|c|c|c|c|}
\hline \multirow[b]{3}{*}{ Factors } & \multicolumn{4}{|c|}{ MYCL1 } & \multirow{2}{*}{\multicolumn{2}{|c|}{$\frac{\text { c-Myc }}{\text { IHC }}$}} \\
\hline & \multicolumn{2}{|c|}{ FISH } & \multicolumn{2}{|c|}{ IHC } & & \\
\hline & Amplified & Non-amplified & Positive & Negative & Positive & Negative \\
\hline \multicolumn{7}{|l|}{ Gender } \\
\hline Male & 2 & 34 & 3 & 33 & 4 & 32 \\
\hline Female & 1 & 9 & 0 & 10 & 0 & 10 \\
\hline \multicolumn{7}{|l|}{ Age } \\
\hline$<60$ & 0 & 24 & 2 & 22 & 2 & 22 \\
\hline$\geq 60$ & 3 & 19 & 1 & 21 & 2 & 20 \\
\hline \multicolumn{7}{|l|}{ Smoking } \\
\hline Non- and light smoker & 1 & 15 & 0 & 16 & 1 & 15 \\
\hline Moderate and heavy smoker & 2 & 28 & 3 & 27 & 3 & 27 \\
\hline \multicolumn{7}{|l|}{ Stage } \\
\hline 1 & 1 & 21 & 3 & 19 & 1 & 21 \\
\hline$\|-I\|$ & 2 & 22 & 0 & 24 & 3 & 21 \\
\hline \multicolumn{7}{|l|}{ Lymph node metastasis } \\
\hline NO & 1 & 21 & 3 & 19 & 1 & 21 \\
\hline $\mathrm{N}+$ & 2 & 22 & 0 & 24 & 3 & 21 \\
\hline \multicolumn{7}{|l|}{ Brain metastasis } \\
\hline No & 3 & 31 & 3 & 31 & 4 & 30 \\
\hline Yes & 0 & 12 & 0 & 12 & 0 & 12 \\
\hline
\end{tabular}

\section{Correlation of L-Myc Protein Expression with MYCL1 amplification and Fusion}

In all 46 SCLC cases, IHC and FISH were performed successfully, the MYCL1 FISH-positive in 3 cases, and L-Myc IHC-positive in 3 cases. However, there was no overlap between L-Myc protein expression and MYCL1 amplification and fusion.

\section{Correlation of MYCL1 amplification, L-Myc Protein and c-Myc Protein Expression}

In all 46 SCLC cases, $4 \mathrm{c}$-Myc-positive cases had no overlap with 3 MYCL1 FISH and 3 L-Myc protein positive cases. No correlations between MYCL1 amplification, L-Myc protein expression and c-Myc protein expression were found.

\section{DISCUSSION}

Little is known about C-MYC and MYCL1 in resected SCLC samples due to rare surgical resection in SCLC. For the first time, postoperative specimens were used in this study to comprehensively analyze MYCL1 amplification, L-Myc and c-Myc protein expressions. Among the 46 evaluated specimens, MYCL1 amplification was identified in 3 of 46 cases (6.5\%). Interestingly, one of the three 
A

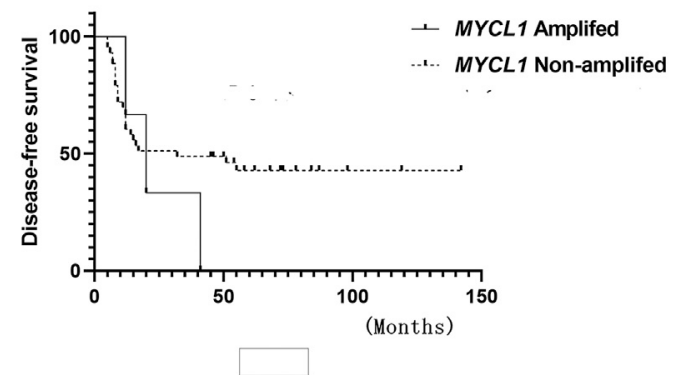

C

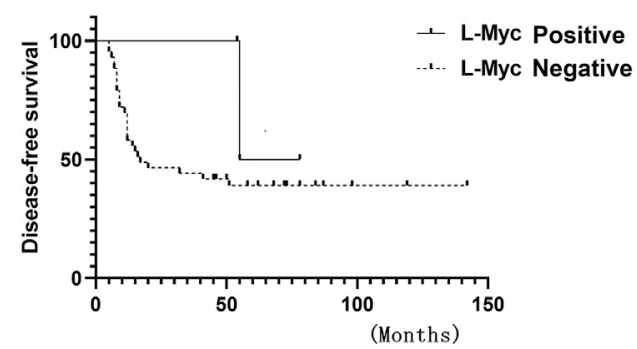

E

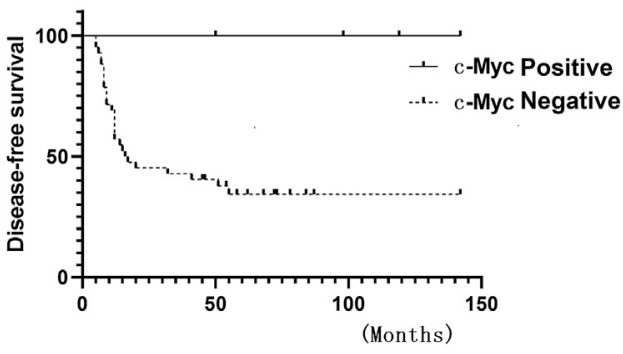

B

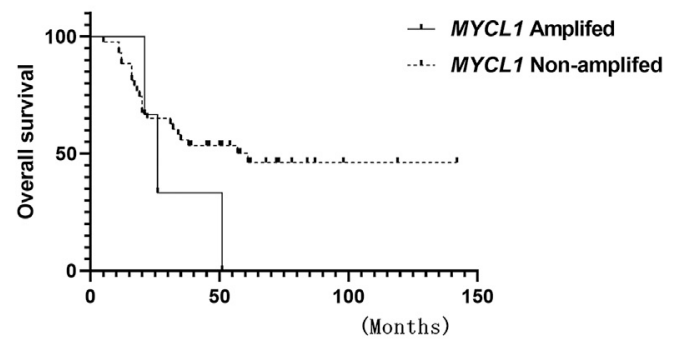

D

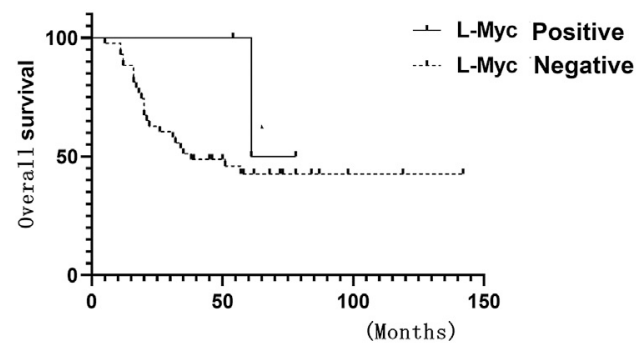

$\mathbf{F}$

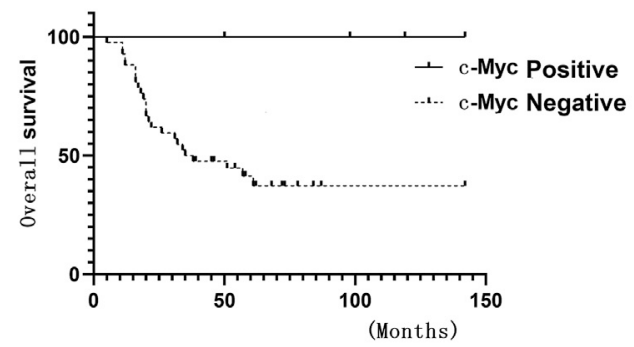

FIGURE 2 | Survival curve (A) Disease-free survival (DFS) of MYCL1 amplification (B) Overall survival (OS) of MYCL1 amplification (C) DFS of L-Myc protein expression (D) OS of L-Myc protein expression (E) DFS of C-Myc protein expression (F) OS of c-Myc protein expression.

positive cases simultaneously had MYCL1 amplification and fusion, which need further explored. 3/46 (6.5\%) specimens were positive for L-Myc protein expression and 4/46 (8.7\%) of the specimens were positive for c-Myc protein expression.

The MYC family has been reported to be amplified in a subset of SCLCs. Recent studies have indicated that C-MYC and MYCL1 may be the potential targets for SCLC, which could modulate the tumor microenvironment and intratumoral heterogeneity in SCLC in vivo and vitro [18, 19]. As had been proved, MYCL1 was tightly related to neuroendocrine cancers, such as SCLC and Merkel cell carcinoma [12, 20]. From all above, C-MYC and MYCL1 play crucial roles in the malignant behaviors of SCLC.

In our cohort, MYCL1 amplification was observed in 6.5\% SCLC cases using FISH, and L-Myc protein expression was observed in $6.5 \%$ of SCLC cases. So far, our study is the first research focus on MYCL1 amplification in SCLC. The prevalence of MYCL1 amplification was in accordance with the data from the genomic profiles of SCLC [5]. However, there was no relation between L-Myc protein expression and high MYCL1 gene copy number in our study although the underlying mechanism was undetermined.

According to IHC results, c-Myc protein expression was identified in $8.7 \%(4 / 46)$ of SCLC patients in our study, which was lower than the results of the following study. It has been reported that $38 \%(39 / 103)$ of SCLC patients showed some degree of c-Myc protein expression. MYC amplification by CISH was observed in 9.3\% (9/97) of SCLC patients, and was correlated with protein expression [7]. Another study suggested that MYC amplification by CISH was detected in $20 \%(11 / 55)$ of SCLCs [21]. Our study only detected c-Myc protein expression, not MYC amplification, so we were unable to confirm the correlation between the c-Myc protein expression and MYC amplification. In addition, in terms of differences of $\mathrm{c}-\mathrm{Myc}$ protein expression, a possible explanation to the discordance might be related to the different disease stage and specimens used. Of 46 SCLC cases in our study, all were larger specimens and all cases were resected with stage I-III, not advanced metastatic SCLC. However, in the other study, 103 SCLC cases with stage I-IV (50\% cases were 


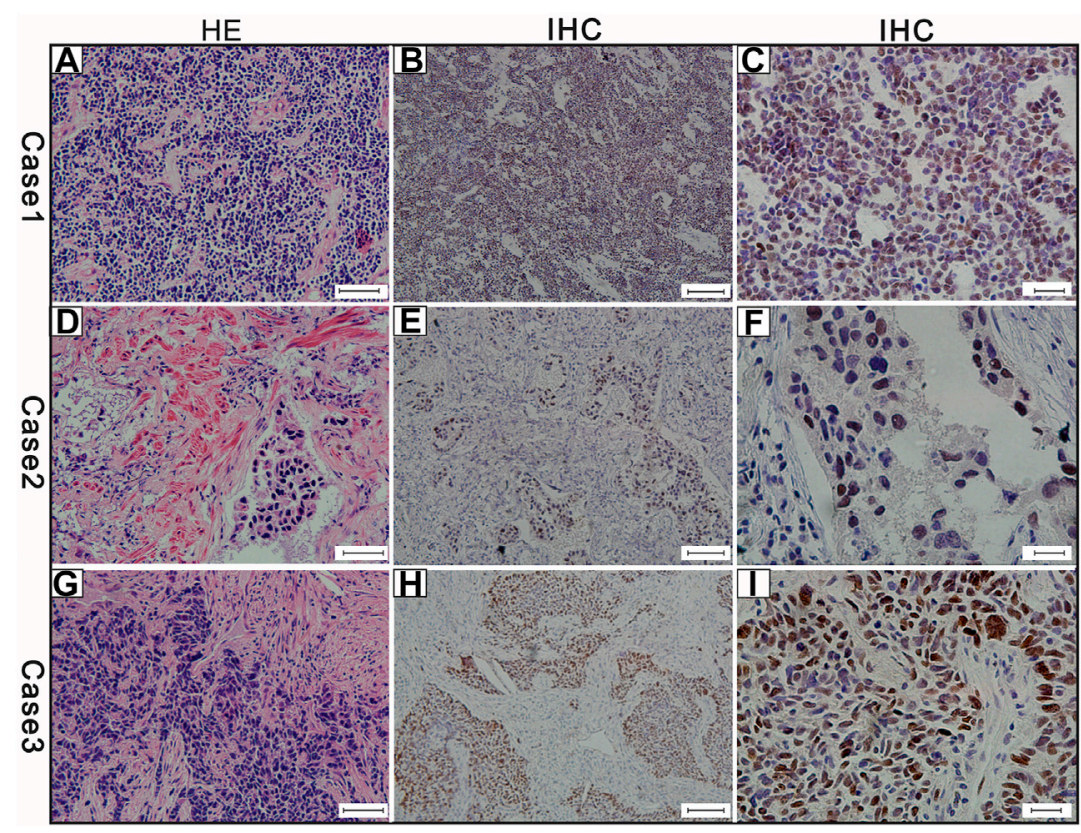

FIGURE 3 | The results of the three cases of c-Myc protein expression (A) Hematoxylin and eosin (H,E)-staining of case-1 (scale bar 50 um) $\mathbf{( B )}$ c-Myc protein positive expression of case-1 (scale bar $100 \mu \mathrm{m}$ ) (C) c-Myc protein expression positive of case-1 (scale bar $20 \mu \mathrm{m})$ (D) Hematoxylin and eosin (H,E)-staining of case-2 (scale bar 50 Hm) (E) c-Myc protein positive expression of case-2 (scale bar $100 \mu \mathrm{m}$ ) (F) c-Myc protein expression positive of case-2 (scale bar $20 \mu \mathrm{m}$ ) (G) Hematoxylin and eosin (H,E)-staining of case-3 (scale bar $50 \mu \mathrm{m}) \mathbf{( H )}$ MYC protein positive expression of case-3 (scale bar $100 \mu \mathrm{m})$ (I) MYC protein expression positive of case3 (scale bar $20 \mu \mathrm{m}$ ). Brown color of the cytoplasm and nucleuses were defined as positive staining.

extensive-stage) were included [7]. The above results suggested that $\mathrm{c}-\mathrm{Myc}$ protein expression may be affected by stage.

However, whether C-MYC and MYCL1 affect the survival remains unascertained in SCLC. Hwang et al. found no statistical relationship between $M Y C$ amplification and $O S$ in the untreated SCLC patients (50\% extensive-stage) [7]. Alves RC et al. reported $M Y C$ amplification was associated with poor survival (4.67 weeks of patients with $M Y C$ amplification vs. 26.15 weeks of patients without $M Y C$ amplification, $p=0.02$ ) in the untreated SCLC patients [22]. It is worth noting that about $85 \%$ of the above SCLC patients were in an advanced stage with a median OS of 22.91 weeks ( 5.7 months), that was shorter than the usual median OS (about 10 months). In addition, their 20\% MYC amplification prevalence was higher than the usual rate (about $7 \%)$. A possible explanation to this discordance might be that a mean of 60 cells were evaluated, which influenced the statistical results. In a study conducted by Chen et al, multivariate analysis results showed that L-Myc expression was an independent prognostic factor of gastric cancer, which suggested that L-Myc expression is a useful biomarker for gastric cancer prediction and a promising therapeutic target for gastric cancer treatment [11]. Additionally, colorectal cancer patients whose tumors exhibited $\mathrm{LOH}$ at MYCL1 on chromosome 1p34 show poor prognosis, which indicated that MYCL1 may be used as a biomarker with clinical relevance [23]. MYCL1 activation might be associated with efficacy and disease relapse. Recent work has shown that longitudinal cell-free DNA (cfDNA) analysis in SCLCs played important roles in revealing dynamic insights into the treatment efficacy and disease relapse. Profiling of patient's
cfDNA prior to first-line chemoradiotherapy revealed MYCL1 amplification (15.5 copies). Following treatment with cisplatin and etoposide, no decrease of amplification level was detected in all serial samples collected up to 413 days after diagnosis, which suggested that the patient had platinum-sensitive disease [22]. The impact of MYCL1 and C-MYC on survival may be too small to be detected. Alternatively, the sample size and baseline differences may also have a bias on outcomes. Therefore, the results are not necessarily objective and reliable. There is another possibility that these biomarkers ultimately maybe contribute to predicting the treatment response in SCLC, rather than to predicting prognosis.

Methods have been found to modulate Myc family pathways through targeted therapy. However, directly targeting Myc family for therapy is still elusive due to lack of a well-established ligandbinding domain. Therefore, much attention has been paid on the targeting downstream regulators. Aurora kinase inhibitor alisertib is hypothesized to be a target of MYCL1 downstream pathway, further focusing on the investigation of MYCL1 fusions in SCLC. Silencing MYCL1 in SCLC cell lines with RLF-MYCL1 fusion results in the decreased cell proliferation [24]. A few SCLC patients may benefit from alisertib, showing promising results in clinic trials $[25,26]$. A total of 689 SCLC patients were assayed with hybrid-capture based comprehensive genomic profiling (CGP). MYCL1 amplification was identified in 53 cases, and six were MYCL1 fusions (MYCL1-COL9A2, MYCL1-MSRB2, MYCL1-PABPC4, MYCL1-MACF1, MYCL1-JAZF1, and one with indeterminate partner). All arose from inter-chromosomal rearrangements. A non-smoker SCLC patient (aged 46 years, male) 
was identified to harbor MYCL1-JAZF1, and had near complete response to alisertib for 18 months following the failure of three previous lines of chemotherapy [25]. Further investigation regarding MYCL1 fusions in SCLC patients is warranted to assess possible functions as oncogenic drivers. Considering the positive effect of alisertib or other therapies targeting MYCL1 pathway, the ability to identify MYCL1 protein expression and amplification or/and fusion might be an essential component of pathological workup. MYCL1 fusion was detected using FISH, which was present in $6.5 \%$ of SCLC patients in this study. However, the IHC results were negative. The status and correlation of MYCL1 fusion and expression in SCLC patients in China are still unknown. Hence, in this paper, MYCL1 fusion and expression were detected in SCLC patients to serve as the basis for precision treatment. Besides, it is noticed that there are abundant lymphocytes infiltrating in the mesenchyme in six cases (L-Myc positive and MYCL1 amplification). Lymphocyte infiltration was closely related to local immune response, which can be used as a biomarker of immunotherapy. It has been reported that MYCL1 selectively expressed in the dendritic cells play an important role in infection immunity and is required for optimal T-cells priming following bacterial and viral infection. Does MYCL1 expressed by cancer cells also activate T-cells to mediate tumor immunity? How does the interaction between MYCL1 and T-cell interference influence on SCLC patient outcomes? These questions are interesting and considerable.

However, our study has some limitations. Although the sample size of our study on postoperative specimens for SCLC is the relatively large, it is still insufficient and the MYCL1-and MYC-positive samples remain few. The significant differences between the clinical characteristics and outcomes of patients with positive and negative groups were not enough to statistical identified. Therefore, we yielded to evaluate clinical characteristics and survival analysis, because the low number of positive cases does not permit reliable evaluation. To identify such factors, a larger sample size of SCLC patients is needed.

In conclusion, our findings from the present study showed that MYCL1 and MYC were infrequently detected in the resected SCLCs. Our study provide information for detection, clinicopathological characteristics, and survival of MYCL1 and c-Myc positive patients with surgically resected SCLC, which makes a contribution to subsequent research and therapeutic strategies. Additional correlative studies with larger cohort are needed to determine whether the protein expression or gene

\section{REFERENCES}

1. Siegel RL, Miller KD, Fuchs HE, and Jemal A. Cancer Statistics, 2021. CA A Cancer J Clin (2021) 71(1):7-33. doi:10.3322/caac.21654

2. Chen W, Zheng R, Baade PD, Zhang S, Zeng H, Bray F, et al. Cancer Statistics in China, 2015. CA: a Cancer J clinicians (2016) 66(2):115-32. doi:10.3322/caac.21338

3. Bernhardt EB, and Jalal SI. Small Cell Lung Cancer. Cancer Treat Res (2016) 170:301-22. doi:10.1007/978-3-319-40389-2_14

4. Iams WT, Porter J, and Horn L. Immunotherapeutic Approaches for Small-Cell Lung Cancer. Nat Rev Clin Oncol (2020) 17(5):300-12. doi:10.1038/s41571-019-0316-Z

5. Iwakawa R, Takenaka M, Kohno T, Shimada Y, Totoki Y, Shibata T, et al. Genome-wide Identification of Genes with Amplification And/or Fusion in amplification is more predictive and/or has prognostic impact on Myc pathway dependency.

\section{DATA AVAILABILITY STATEMENT}

The original contributions presented in the study are included in the article, further inquiries can be directed to the corresponding author.

\section{ETHICS STATEMENT}

This study was approved by the Medical Ethical Committee of Zhejiang Cancer Hospital. Most of the patients in this retrospective study signed the written informed consent before surgery to preserve their specimens in the Biological Sample Bank of Zhejiang Cancer Hospital to be used in research. This study is a retrospective study and some patients had died, exempt written informed consent was also approved by the Ethics Committee of Zhejiang Cancer Hospital.

\section{AUTHOR CONTRIBUTIONS}

All authors listed have made a substantial, direct, and intellectual contribution to the work and approved it for publication.

\section{FUNDING}

This work was supported by National Natural Science Foundation of China (No.81903981), Zhejiang Province Medical Science Fund Project of China (No. 2020382893, 2020ZH001 and 2018KY307), Zhejiang Provincial Natural Science Foundation of China (No. Y21H290002 and LY20H290003), and the 1022 Talent Training Program of Zhejiang Cancer Hospital

\section{CONFLICT OF INTEREST}

The authors declare that the research was conducted in the absence of any commercial or financial relationships that could be construed as a potential conflict of interest.

Small Cell Lung Cancer. Genes Chromosomes Cancer (2013) 52(9):802-16. doi:10.1002/gcc. 22076

6. Ireland AS, Micinski AM, Kastner DW, Guo B, Wait SJ, Spainhower KB, et al. MYC Drives Temporal Evolution of Small Cell Lung Cancer Subtypes by Reprogramming Neuroendocrine Fate. Cancer cell (2020) 38(1):60-78. doi:10.1016/j.ccell.2020.05.001

7. Hwang DH, Sun H, Rodig SJ, Hornick JL, and Sholl LM. Myc Protein Expression Correlates withMYCamplification in Small-Cell Lung Carcinoma. Histopathology (2015) 67(1):81-9. doi:10.1111/his.12622

8. Wasylishen AR, Stojanova A, Oliveri S, Rust AC, Schimmer AD, and Penn LZ. New Model Systems Provide Insights into Myc-Induced Transformation. Oncogene (2011) 30(34):3727-34. doi:10.1038/ onc. 2011.88 
9. Nakagawa M, Takizawa N, Narita M, Ichisaka T, and Yamanaka S. Promotion of Direct Reprogramming by Transformation-Deficient Myc. Proc Natl Acad Sci (2010) 107(32):14152-7. doi:10.1073/pnas.1009374107

10. Kc W, Satpathy AT, Rapaport AS, Briseño CG, Wu X, Albring JC, et al. L-myc Expression by Dendritic Cells Is Required for Optimal T-Cell Priming. Nature (2014) 507(7491):243-7. doi:10.1038/nature12967

11. Chen S, Tang J, Huang L, and Lin J. Expression and Prognostic Value of Mycl1 in Gastric Cancer. Biochem biophysical Res Commun (2015) 456(4):879-83. doi:10.1016/j.bbrc.2014.12.060

12. Borromeo MD, Savage TK, Kollipara RK, He M, Augustyn A, Osborne JK, et al. ASCL1 and NEUROD1 Reveal Heterogeneity in Pulmonary Neuroendocrine Tumors and Regulate Distinct Genetic Programs. Cel Rep (2016) 16(5):1259-72. doi:10.1016/j.celrep.2016.06.081

13. Xiong F, Wu C, Chang J, Yu D, Xu B, Yuan P, et al. Genetic Variation in an miRNA-1827 Binding Site in MYCL1 Alters Susceptibility to Small-Cell Lung Cancer. Cancer Res (2011) 71(15):5175-81. doi:10.1158/0008-5472.CAN-10-4407

14. Kim YH, Girard L, Giacomini CP, Wang P, Hernandez-Boussard T, Tibshirani $\mathrm{R}$, et al. Combined Microarray Analysis of Small Cell Lung Cancer Reveals Altered Apoptotic Balance and Distinct Expression Signatures of MYC Family Gene Amplification. Oncogene (2006) 25(1):130-8. doi:10.1038/ sj.onc. 1208997

15. Travis WD, Brambilla E, Nicholson AG, Yatabe Y, Austin JHM, Beasley MB, et al.WHO Panel. The 2015 World Health Organization Classification of Lung Tumors. J Thorac Oncol (2015) 10(9):1243-60. doi:10.1097/ JTO.0000000000000630

16. Nicholson AG, Chansky K, Crowley J, Beyruti R, Kubota K, Turrisi A, et al. Staging and Prognostic Factors Committee, Advisory Boards, and Participating Institutions, \& Staging and Prognostic Factors Committee Advisory Boards and Participating InstitutionsThe International Association for the Study of Lung Cancer Lung Cancer Staging Project: Proposals for the Revision of the Clinical and Pathologic Staging of Small Cell Lung Cancer in the Forthcoming Eighth Edition of the TNM Classification for Lung Cancer. J Thorac Oncol : official Publ Int Assoc Study Lung Cancer (2016) 11(3):300-11. doi:10.1016/j.jtho.2015.10.008

17. Tian X, Xu J, and Dorfman DM. Utility of Combined EZH2, P-Erk1/2, P-STAT, and MYC Expression in the Differential Diagnosis of EZH2Positive Hodgkin Lymphomas and Related Large B-Cell Lymphomas. Am J Surg Pathol (2019) 43(1):102-9. doi:10.1097/PAS.0000000000001180

18. Kato F, Fiorentino FP, Alibés A, Perucho M, Sánchez-Céspedes M, Kohno T, et al. MYCL Is a Target of a BET Bromodomain Inhibitor, JQ1, on Growth Suppression Efficacy in Small Cell Lung Cancer Cells. Oncotarget (2016) 7(47): 77378-88. doi:10.18632/oncotarget.12671
19. Brägelmann J, Böhm S, Guthrie MR, Mollaoglu G, Oliver TG, and Sos ML. Family Matters: How MYC Family Oncogenes Impact Small Cell Lung Cancer. Cell Cycle (2017) 16(16):1489-98. doi:10.1080/15384101.2017.1339849

20. Cheng J, Park DE, Berrios C, White EA, Arora R, Yoon R, et al. Merkel Cell Polyomavirus Recruits MYCL to the EP400 Complex to Promote Oncogenesis. Plos Pathog (2017) 13(10):e1006668e1006668. doi:10.1371/ journal.ppat.1006668

21. Alves RC, Meurer RT, and Roehe AV. MYC Amplification Is Associated with Poor Survival in Small Cell Lung Cancer: a Chromogenic In Situ Hybridization Study. J Cancer Res Clin Oncol (2014) 140(12):2021-5. doi:10.1007/s00432014-1769-1

22. Almodovar K, Iams WT, Meador CB, Zhao Z, York S, Horn L, et al. Longitudinal Cell-free DNA Analysis in Patients with Small Cell Lung Cancer Reveals Dynamic Insights into Treatment Efficacy and Disease Relapse. J Thorac Oncol (2018) 13(1):112-23. doi:10.1016/ j.jtho.2017.09.1951

23. Kambara T, Sharp GB, Nagasaka T, Takeda M, Sasamoto H, Nakagawa H, et al. Allelic Loss of a Common Microsatellite Marker MYCL1. Clin Cancer Res (2004) 10(5):1758-63. doi:10.1158/1078-0432.ccr-0779-3

24. Rudin CM, Durinck S, Stawiski EW, Poirier JT, Modrusan Z, Shames DS, et al. Comprehensive Genomic Analysis Identifies SOX2 as a Frequently Amplified Gene in Small-Cell Lung Cancer. Nat Genet (2012) 44(10):1111-6. doi:10.1038/ng.2405

25. Sos ML, Dietlein F, Peifer M, Schöttle J, Balke-Want H, Müller C, et al. A Framework for Identification of Actionable Cancer Genome Dependencies in Small Cell Lung Cancer. Proc Natl Acad Sci (2012) 109(42):17034-9. doi:10.1073/pnas.1207310109

26. Melichar B, Adenis A, Lockhart AC, Bennouna J, Dees EC, Kayaleh O, et al. Safety and Activity of Alisertib, an Investigational aurora Kinase A Inhibitor, in Patients with Breast Cancer, Small-Cell Lung Cancer, Nonsmall-cell Lung Cancer, Head and Neck Squamous-Cell Carcinoma, and Gastro-Oesophageal Adenocarcinoma: a Five-Arm Phase 2 studyThe Lancet. Lancet Oncol (2015) 16(4):395-405. doi:10.1016/S1470-2045(15) 70051-3

Copyright (c) 2021 Qin, Xie, Li, Han and Lu. This is an open-access article distributed under the terms of the Creative Commons Attribution License (CC BY). The use, distribution or reproduction in other forums is permitted, provided the original author(s) and the copyright owner(s) are credited and that the original publication in this journal is cited, in accordance with accepted academic practice. No use, distribution or reproduction is permitted which does not comply with these terms. 